\title{
Sturgeon: Conservation of Caspian Sea Stocks
}

\section{Mahmoudreza Ovissipour and Barbara Rasco*}

School of Food Science, Washington State University, Pullman, WA, USA

The Caspian Sea is surrounded by five countries: Azerbaijan, Iran, Kazakhstan, the Russian Federation and Turkmenistan. It has traditionally been known as the sea of sturgeon and produces more than $90 \%$ of the world's caviar. Five species of sturgeons are the most live in the Caspian Sea including: beluga (Huso huso), Persian sturgeon (Acipenser persicus), Russian sturgeon (A. gueldenstaedtii), ship (A. nudiventris), and sevruga (A. stellatus). These are all anadromous meaning that they spend most of their life in Caspian Sea but enter the adjacent rivers Volga, Ural, Kura, Sefidroud, Tajan, Gorgan and Atrak that constitute the major natural spawning ground for these species. The roe of these fishes is processed into caviar, one of the most expensive luxury food items with meat, skin, notochord and isinglass being secondary products. Common trade names for caviar vary by species with ossetra coming from the Persian sturgeon, Russian sturgeon and ship sturgeon and sevruga and beluga from the fish species bearing that name. Unfortunately, the total catch of sturgeon has dropped substantially in recent years from 25,000-30,000 metric tons between 1975 and 1985 to 15,000-16,000 metric tons between 1990 and 1992, and in 2000, no more than 2,000 metric tons. Specifically for Iran, the total sturgeon catch and caviar production in Iran in 1993 was 1,710 and 106 tons, while in 2009 it decreased $90 \%$ to 178.41 and less than 10 tons, respectively. Natural sturgeon populations worldwide are decreasing due to the overfishing, use of non-selective gears, or inappropriate open seasons, decrease in natural reproduction resulted from a reduction of the river flow because of dams, a drop in seawater level and environmental pollution from industrial and agricultural origins. For example, spawning areas in the Volga River have dropped from 3,390 ha to 430 ha, and the Kura, Tajan, Gorgan and Sefidroud rivers are no longer suitable for spawning.

Illegal harvest constitutes approximately $50 \%$ of total catch. Political factors have played a major role and the collapse of the Soviet Union has negatively affected management of the fisheries in what had previously been between two littoral countries (The USSR and Iran) to the current five. Loss of economic opportunity and social control of the fisheries in these newly independent republics, has led to widespread poaching by coastal inhabitants and great damage to Caspian fishery resources overall but especially to the sturgeon species. After the collapse of the Soviet state, no international agreement has been reached on the regulation of sturgeon catches among the countries bordering the Caspian Sea despite pressure from the international community; therefore there has been no effective fishery management system for the past twenty years and the associated control, monitoring and surveillance of fishing activities.

The fishery is now in dire straits and extinction has become a real possibility. Suitable conservation and management strategies for sturgeon stocks in Caspian Sea could be applied, that will allow for a viable fishery and provide a livelihood for local, particularly artisanal fishers. The development of artificial hatchery centers for sturgeon is one the most important tasks which to manage the sturgeon stock and these have had limited success. There are 11 hatcheries in Russian Federation, 5 in Iran and 3 in Azerbaijan, some are very active and some are not and restoration would move along much more quickly if these facilities had the resources they needed to operate at maximum capacity. The total cost for one $3 \mathrm{~g}$ Persian sturgeon fingerling is \$0.5 USD so much could be accomplished with even $\$ 10-50 \mathrm{M}$ annually. Iran has the most effective hatchery system with several facilities: Woshmgear (300 ha), Siahcal (210 ha), Beheshti (110 ha), Rajai (77 ha), and Marjani (45 ha) producing 20 million sturgeon fingerlings annually. Mature fish are harvested by gill net, transferred into the hatchery for recovery of eggs and milt. Unfortunately, adult recruitment has decreased from $3 \%$ to less than $0.01 \%$ because of increasing water pollution and loss of feed from invasion of Ctenophore (Mnemiopsis leidyi) introduced from the Volga and Black Sea into the Caspian Sea which feeds on anchovy eggs and larvae and has caused a collapse in the anchovy stocks in Caspian Sea. Anchovy fishing also provides an important source of income for fishermen in Iran and this collapse led to greater fishing pressure on both stocks and a substantial decrease in the catch per unit effort which has encouraged poaching.

More must be done to restore and then to manage these sturgeon stocks. An analysis of current statues of sturgeon populations throughout the Caspian Sea should be conducted immediately, and with this, the ability to monitor population genetics of sturgeon to determine the determine degree of genetic diversity, prevent illegal catch, create and maintain natural reproduction areas, and develop improved aquaculture systems for sturgeon fry and brood stock that can help to restore natural populations and decrease pressure on the natural population. Development of new methods for artificial propagation especially non-invasive methods for early sex identification, non-lethal surgical removal of roe, improved larvae and brood stock rearing, nutrition, and disease control are needed in hatcheries, since artificial propagation from captive stock is not successful. Preservation of the remaining genetic diversity is a desperate need, with the creation of sperm and embryo banks. From a caviar production standpoint, finding the fish that can yield high quality marketable caviar in shorter periods such as sterlet (A. ruthenus), and establishment of alliance among the countries surrounded by Caspian Sea to market a sustainable caviar is important. Uniform and consistent fisheries enforcement of selective fishing gear based on the sturgeon species, size, age and biology is needed with uniform gear specifications, currently gill-net mesh size of $280 \mathrm{~mm}$ (beluga), $150 \mathrm{~mm}$ (Persian and Russian sturgeon) and 100 $\mathrm{mm}$ (sevruga).

In the past 15 years, Iran has established a new program for sturgeon aquaculture in ponds, basins, net cages and concrete tanks to raise sturgeon for caviar and meat decreasing the pressure on natural population. After 10 years of beluga rearing, high quality roe both in

*Corresponding author: Dr. Barbara Rasco, School of Food Science, Washington State University, Pullman, WA, USA, E-mail: mrovissi@yahoo.com; barbara.rasco@gmail.com

Received November 20, 2012; Accepted November 20, 2012; Published November 30, 2012

Citation: Ovissipour M, Rasco B (2012) Sturgeon: Conservation of Caspian Sea Stocks. J Aquacult Res Dev 3:e104 doi:10.4172/2155-9546.1000e104

Copyright: (c) 2012 Ovissipour M, et al. This is an open-access article distributed under the terms of the Creative Commons Attribution License, which permits unrestricted use, distribution, and reproduction in any medium, provided the original author and source are credited. 
artificial propagation and caviar production has been achieved. In 2004, Iran received 1 to $3 \mathrm{~g}$ sterlet (A. ruthenus) fingerlings from Hungary and reared them in concrete tanks and ponds. High quality eggs for artificial propagation and caviar production were achieved within 4 years. In addition, Iran has the sperm-bank program to improve the sturgeon stock management. Finding alternative income sources for fisherman, such as involving them in sturgeon aquaculture, for example managing larval grow-out facilities for stocking into the Caspian and raising or ranching sturgeon or other fishes could provide income and provide the fishers with income in their home communities. 